\title{
Inotuzumab Ozogamicin
}

National Cancer Institute

\section{Source}

National Cancer Institute. Inotuzumab Ozogamicin. NCI Thesaurus. Code C71542.

A CD22-targeted cytotoxic immunoconjug ate composed of a humanized Ig G4 antiCD22 antibody covalently linked to $\mathrm{N}$-acetyl-gamma-calicheamicin dimethyl hydrazide (CalichDMH) with potential antineoplastic activity. Inotuzumab ozogamicin is rapidly internalized upon binding of the antibody moiety to B cell-specific CD22 receptors, delivering the conjug ated CalichDMH intracellularly; the CalichDMH moiety binds to the minor groove of DNA in a sequence-specific manner, resulting in double-strand DNA breaks and apoptosis. CalichDMH is a derivative of gamma calicheamicin, a cytotoxic antibiotic produced by the bacterium Micromonospora echinospora. 